\title{
Primary osteoathrosis of the hip and Heberden's nodes
}

\author{
J. S. MARKS, I. M. STEWART, AND K. HARDINGE \\ From the Wrightington Hospital, Wigan, Lancs
}

SUMMARY One hundred patients with primary osteoarthrosis of the hip were examined for evidence of generalised arthrosis associated with Heberden's nodes, and in addition their hips were graded by the radiographic pattern of loss of joint space. Twenty-nine patients had bilateral concentric loss of joint space, and 18 in this group had Heberden's nodes. None of the 17 patients with bilateral upper pole changes had Heberden's nodes, and only 7 of the 31 patients with unilateral upper pole changes had Heberden's nodes. None of the 6 patients with medial loss of joint space had Heberden's nodes. This study has shown an association between Heberden's nodes had primary osteoarthrosis of the hip where this is characterised by concentric loss of joint space. The association is most marked where hip changes are bilateral, suggesting that hip involvement in generalised osteoarthrosis is part of a generalised disorder with possible genetic or biochemical abnormalities.

Osteoarthrosis of the hip is a common disorder, present in about $20 \%$ of people over the age of 55 (Kellgren, 1961). Traditionally osteoarthrosis has been separated into primary and secondary types, the latter term being applied where a local antecedent abnormality such as congenital dislocation, old Perthe's disease, or slipped femoral epiphysis can be identified. Primary osteoarthrosis of the hip has been attributed to acetabular dysplasia (Wiberg, 1939; Lloyd-Roberts, 1955), tilt deformity of the femoral head (Murray, 1965) or to leg-length inequality (Gofton, 1971a), and because these theories suggest that the disease is related to incongruity of the hip joint surfaces one would not expect any associated involvement of other peripheral joints. The alternative explanation that there is a biochemical abnormality in the articular cartilage which predisposes the hip to premature degenerative changes (Mankin and Lipcello, 1970) would, however, be associated with polyarticular osteoarthrosis.

The present study has been undertaken to determine the frequency of peripheral joint involvement in primary osteoarthrosis of the hip, to relate the findings to the pattern of radiographic changes in the hip, and to determine whether there are specific patterns of involvement within the group as a whole.

Accepted for publication 12 May 1978.

Correspondence to Dr J. S. Marks, Hope Hospital, Eccles Old Road, Salford M6 8HD

\section{Patients and methods}

Patients with primary osteoarthrosis of the hips admitted to hospital consecutively over a 3-month period for total joint replacement were examined by a single observer (I.M.S.) for evidence of generalised osteoarthrosis, with particular attention being paid to the presence of Heberden's nodes. Patients showing evidence of inflammatory synovitis were excluded. Radiographs of the hands were graded for generalised osteoarthrosis by means of the Atlas of Standard Radiographs (Jeffrey et al., 1963), and patients showing rheumatoid-like erosions were excluded. Heberden's nodes were then recorded as being absent, mild, or moderate/severe by means of a combination of the clinical and radiographic findings. All the patients with Heberden's nodes had clinical or radiographic involvement of at least 2 other joint groups.

The radiographs of the hips were classified by another observer (J.S.M.) who was blind with regard to the clinical findings. The hips were graded by the pattern of joint space narrowing shown on the earliest abnormal $x$-ray films that were available. Patients showing evidence of sacroiliitis, Paget's disease, or chondrocalcinosis of the hip or symphysis pubis were excluded. Four distinct patterns of loss of joint space could be identified, namely, upper pole (Figs. 1, 2), concentric (Figs. 3, 4), medial pole (Fig. 5), or destructive (Fig. 6). 
Fig. 1 Upper pole grade I. Joint space narrow or absent at upper pole. Femoral head flattened by wear at upper pole. Osteophytosis medially with some lateral displacement of head. Shenton's line intact.

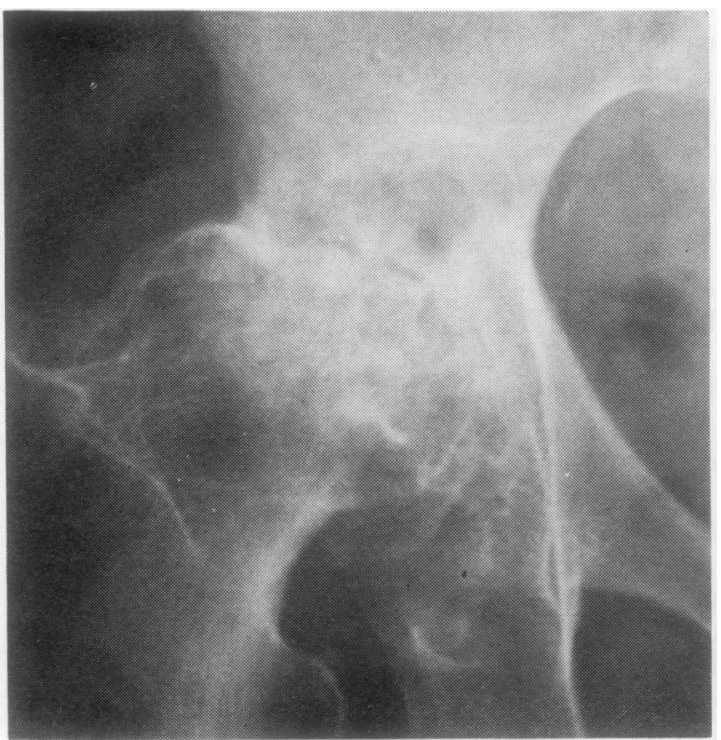

Fig. 2 Upper pole grade II. Gross loss of head substance at upper pole. Secondary subluxation indicated by breakage of Shenton's line.
Fig. 3 Concentric. Joint space narrow or absent concentrically. Femoral head spherical without destruction No protrusio.

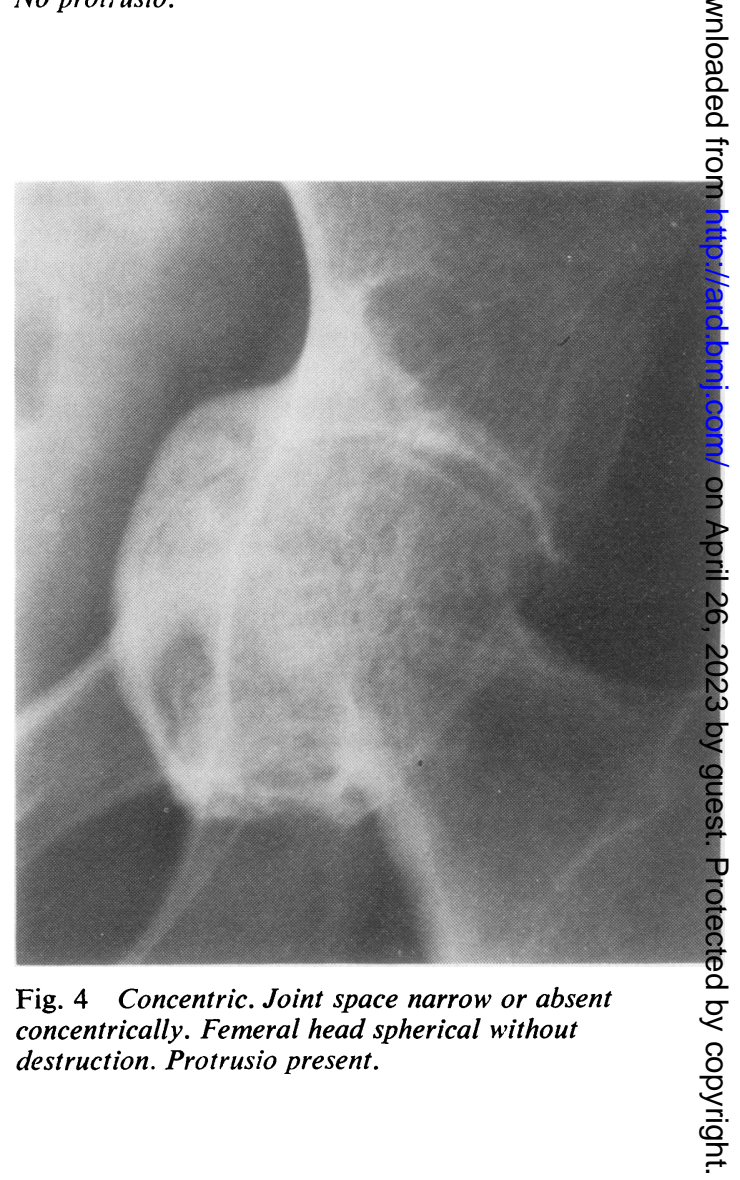




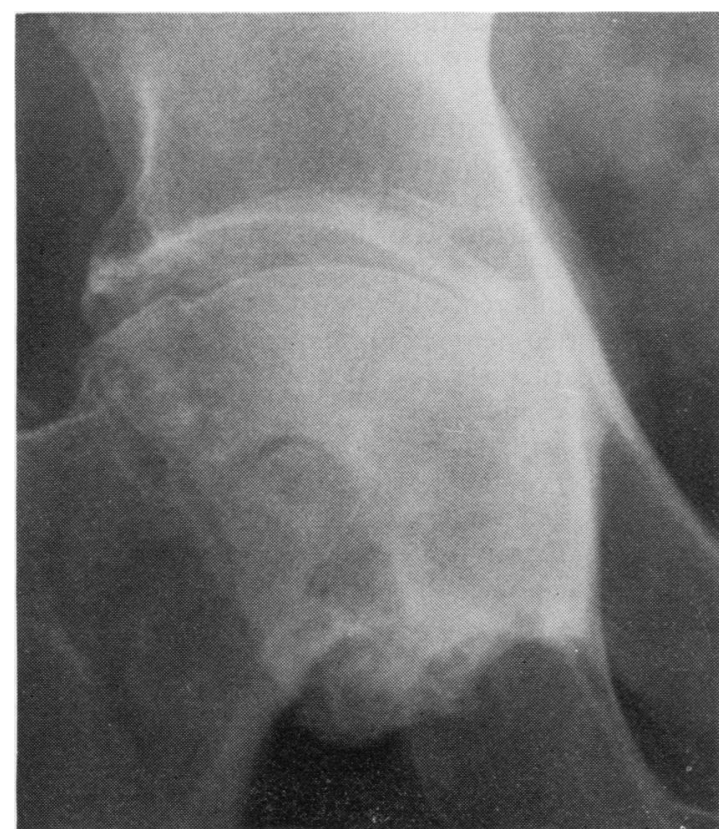

Fig. 5 Medial pole. Good joint space at upper pole but narrow or absent medially. No bulging of pelvic aspect of acetabulum.
The presence of generalised osteoarthrosis of the nodal type was then related to the pattern of radiographic changes in the hips.

\section{Results}

One hundred patients (44 men, 56 women) were included in the study, and Heberden's nodes were present in 29 patients, being mild in 10 and severe in 19. The age and sex distribution of the patients are shown (Table 1). They indicate that the men were younger and that Heberden's nodes were more frequent in the older women.

The relationship between the presence of Heberden's nodes and the patterns of joint space narrowing is shown in Table 2. Six hips could not be classified in patients admitted for conversion of failed osteotomies where the original preoperative $x$-rays were not available, but all had concentric changes in the contralateral hip. Concentric loss of joint space is mainly bilateral, and $62 \%$ of this group had Heberden's nodes, which were present independently of acetabular protrusion. Upper pole changes were commonly unilateral, and only $16 \%$ in this group had Heberden's nodes which were unrelated to the degree of upper pole change. None of the 17 patients with bilateral upper pole changes had Heberden's nodes. The association between

Table 1 Frequency of Heberden's nodes

\begin{tabular}{|c|c|c|c|c|c|c|}
\hline \multirow[b]{2}{*}{ Age } & \multicolumn{3}{|l|}{ Males } & \multicolumn{3}{|l|}{ Females } \\
\hline & $\begin{array}{l}\text { Total } \\
\text { Examined }\end{array}$ & Mild & Severe & $\begin{array}{l}\text { Total } \\
\text { Examined }\end{array}$ & Mild & Severe \\
\hline$<65$ & 23 & 1 & 2 & 16 & 1 & 1 \\
\hline $65-74$ & 16 & 2 & 1 & 28 & 4 & 8 \\
\hline$>74$ & 5 & 1 & 1 & 12 & $i$ & 7 \\
\hline
\end{tabular}

Table 2 Relation between Heberden's nodes and the patterns of joint space loss (100 patients)

\begin{tabular}{|c|c|c|c|c|}
\hline \multirow[t]{2}{*}{$X$-ray grading } & \multirow[b]{2}{*}{$\begin{array}{l}\text { Total } \\
\text { number }\end{array}$} & \multicolumn{3}{|c|}{ Heberden's nodes } \\
\hline & & $\begin{array}{l}\text { Total } \\
\text { number }\end{array}$ & Mild & Severe \\
\hline Unilateral upper pole, Grade I & 8 & 1 & 0 & 1 \\
\hline Unilateral upper pole, Grade II & 23 & 4 & 0 & 4 \\
\hline Bilateral upper pole & 17 & 0 & $\mathbf{0}$ & $\mathbf{0}$ \\
\hline $\begin{array}{l}\text { Bilateral concentric without } \\
\text { protrusio }\end{array}$ & 20 & 14 & 7 & 7 \\
\hline $\begin{array}{l}\text { Bilateral concentric with } \\
\text { protrusio }\end{array}$ & 6 & 3 & 0 & 3 \\
\hline Bilateral concentric with & & & & \\
\hline $\begin{array}{l}\text { unilateral protrusio } \\
\text { Upper pole/concentric }\end{array}$ & $\begin{array}{l}3 \\
7\end{array}$ & $\begin{array}{l}1 \\
1\end{array}$ & $\begin{array}{l}1 \\
0\end{array}$ & $\begin{array}{l}0 \\
1\end{array}$ \\
\hline Concentric/destructive & 2 & 1 & 0 & 1 \\
\hline Concentric/unclassified & 6 & 3 & 1 & 2 \\
\hline Bilateral medial pole & 2 & $\mathbf{0}$ & 0 & 0 \\
\hline Medial pole/upper pole & 4 & 0 & 0 & $\mathbf{0}$ \\
\hline Unilateral destructive & 1 & 1 & 1 & $\mathbf{0}$ \\
\hline Unilateral concentric & 1 & 0 & 0 & 0 \\
\hline
\end{tabular}

Fig. 6 Destructive. Gross loss of head substance. Acetabular destruction not so marked. Element of subluxation. May be sclerosis. 
Table 3 Relation between Heberden's nodes and hip changes in males and females

\begin{tabular}{llllll}
\hline & \multicolumn{2}{l}{ Males } & & \multicolumn{2}{l}{ Females } \\
\cline { 2 - 5 } \cline { 5 - 6 } & $\begin{array}{l}\text { Nodes } \\
\text { present }\end{array}$ & $\begin{array}{l}\text { Nodes } \\
\text { absent }\end{array}$ & $\begin{array}{l}\text { Nodes } \\
\text { present }\end{array}$ & $\begin{array}{l}\text { Nodes } \\
\text { absent }\end{array}$ \\
\hline Unilateral upper pole & 1 & 12 & 4 & 14 \\
Bilateral upper pole & 0 & 10 & & 7 \\
Bilateral concentric & 5 & 4 & 13 & 7 \\
\hline
\end{tabular}

Heberden's nodes and concentric loss of joint space was statistically significant in both sexes $\mathbf{P}<0.005$ (Table 3). Analysis of the bilateral concentric group for hip osteophytes showed moderate to severe osteophytes in 8 out of 18 cases with Heberden's nodes $(44 \%)$ and 5 of 11 cases without Heberden's nodes $(45 \%)$.

\section{Discussion}

We have attempted a classification of primary osteoarthrosis of the hip based on the radiographic pattern of joint space narrowing and could define 4 types, namely, upper pole, concentric, medial pole, and destructive. Unlike other workers (Gofton, 1971b; Resnick, 1975) we did not attempt to distinguish between superolateral and superomedial loss of joint space and graded all patients with superior loss of joint space in the upper pole group. Most $x$-rays of the hips were not taken in the weightbearing position, so that the definition of the degree of joint space loss is somewhat arbitrary. But because we have studied a group of patients selected for hip surgery the changes in their hips were usually advanced, and joint space narrowing was unequivocal. All patients were graded by means of the earliest abnormal radiographs that were available, and with the exception of 3 patients who initially showed concentric loss but then developed upper pole changes there was no interchange on serial films between the 4 different patterns of loss.

We have found that concentric loss of joint space is mainly bilateral and related to generalised osteoarthrosis of the nodal type, but we were unable to show any association between the other patterns of joint space narrowing and generalised osteoarthrosis.

An association between generalised osteoarthrosis and Heberden's nodes has been confirmed in population studies, but no statistically significant difference was found between the incidence of osteoarthrosis of the hip in patients with and without Heberden's nodes (Kellgren and Lawrence, 1958). In a study of genetic factors the hip was the only joint not affected more often by osteoarthrosis than expected in the relatives of probands with generalised osteoarthrosis (Kellgren et al., 1963). previous attempt to classify patients with arthritis. of the hip suitable for prosthetic replacement was unable to demonstrate any distinct disease entig (Byers et al., 1975), and another study failed to show a relationship between Heberden's nodes ang primary osteoarthrosis of the hip in patients attend ing an orthopaedic outpatient clinic (Yazici et atos 1975). The difference between these results and the study reported here may be explained by the failure of these earlier studies adequately to classify th $x$-ray changes in the hips, but our results are in close agreement with a radiological survey of osteof arthrosis of the hip in a random population samphe which reported a relation between Heberden's nodes and hip radiographs characterised by marked osteophyte formation and minimal deformity of the femoral head or acetabulum (Kellgren and Lawrence 1961).

There has been a tendency in the past to group alf cases of primary osteoarthrosis of the hip together. as if they represented a single disease entity. In the study patients with upper pole loss of joint space usually had unilateral hip changes and a low incidence of Heberden's nodes, suggesting the upper pole changes may be secondary to local mechanical factors in the affected hip. Our resulf show that by a combined clinical and radiographio study it is possible to distinguish a characteristic subgroup with concentric loss of joint space which is bilateral and associated with Heberden's nodes, suggesting that the hip changes are related to biof chemical or genetic factors. Confirmation that thie concentric group represents a distinct disease entity will require the establishment of a specifie natural history and characteristic pathological change.

\section{References}

Byers, P. D., Roper, B. A., and Glennie, B. (1975). Attem to classify patients with arthritis of the hip suitable for prosthetic replacement and their femoral heads. Annals of the Rheumatic Diseases, 34, 298-302.

Gofton, J. P. (1971a). Studies in osteoarthritis of the hiv Part II : Osteoarthritis of the hip and leg-length disparit to Canadian Medical Association Journal, 104, 791-799.

Gofton, J. P. (1971b). Studies in osteoarthritis of the hip. Part I: Classification. Canadian Medical Associatiof Journal, 104, 679-683.

Jeffrey, M. R., Kellgren, J. H., and Ball, J. R. (1963). Atlas of Standard Radiographs. Epidemiology of Chronta Rheumatism. Vol. II. Edited by J. H. Kellgren. Blackweß̈ Publications: Oxford.

Kellgren, J. H. (1961). Osteoarthrosis in patients and populations. British Medical Journal, 2, 1-6.

Kellgren, J. H., and Lawrence, J. S. (1958). Osteoarthros and disc degeneration in an urban population. Annals of the Rheumatic Diseases, 17, 388-397. 
Kellgren, J. H., and Lawrence, J. S. (1961). Osteoarthrosis of the hip in random population samples. Atti del $X$ Congresso della Lega Internazionale il Rheumatismo, 2, Communicazioni, 366-368. Minerva Medica: Torino.

Kellgren, J. H., Lawrence, J. S., and Bier, F. (1963). Genetic factors in generalised osteoarthrosis. Annals of the Rheumatic Diseases, 22, 237-255.

Lloyd-Roberts, G. C. (1955). Osteoarthritis of the hip. A study of the clinical pathology. Journal of Bone and Joint Surgery, 37B, 8-47.

Mankin, H. J., and Lipiello, L. (1970). Biochemical and metabolic abnormalities in articular cartilage from osteoarthritic human hips. Journal of Bone and Joint Surgery, 52A, 424-434.
Murray, R. O. (1965). The aetiology of primary osteoarthritis of the hip. British Journal of Radiology, 50, 81-83.

Resnick, D. (1975). Patterns of migration of the femoral head in osteoarthritis of the hip. American Journal of Roentgenology, Radium Therapy and Nuclear Medicine, 124, 62-74.

Wiberg, G. (1939). Studies of dysplastic acetabula and congenital subluxation of the hip joint. Acta Chirurgica Scandinavica, 83, Supplement 58.

Yazici, H., Saville, P. D., Salvati, E. A., Bohne, W.H.O., and Wilson, P. D. (1975). Primary osteoarthrosis of the knee or hip. Prevalence of Heberden's nodes in relation to age and sex. Journal of the American Medical Association, 231, 1256-1260. 